\title{
Coulisses
}

Revue de théâtre

19 | Hiver 1999

Varia

\section{Le Théâtre dans le théâtre. Le cinéma au cinéma}

Textes réunis et présentés par Frank Wilhelm - Éd. Lansman, Luxembourg, 1998

Philippe Baron

\section{(2) OpenEdition}

1 Journals

Édition électronique

URL : https://journals.openedition.org/coulisses/5800

DOI : $10.4000 /$ coulisses.5800

ISSN : 2546-9460

Éditeur

Presses universitaires de Franche-Comté

\section{Édition imprimée}

Date de publication : 1 janvier 1999

Pagination : 71

ISBN : 2-913322-09-3

ISSN : $1150-594 X$

\section{Référence électronique}

Philippe Baron, "Le Théâtre dans le théâtre. Le cinéma au cinéma », Coulisses [En ligne], 19 | Hiver 1999, mis en ligne le 18 octobre 2019, consulté le 05 janvier 2022. URL : http://journals.openedition.org/ coulisses/5800; DOI : https://doi.org/10.4000/coulisses.5800

Ce document a été généré automatiquement le 5 janvier 2022.

Coulisses 


\section{Le Théâtre dans le théâtre. Le cinéma au cinéma}

Textes réunis et présentés par Frank Wilhelm - Éd. Lansman, Luxembourg, 1998

\section{Philippe Baron}

1 Le Centre d'études et de recherches francophones du Centre universitaire de Luxembourg a organisé en 1995 un fort intéressant colloque sur ce sujet. Les lecteurs de Coulisses auront certainement envie de lire les actes qui viennent de paraitre sous le même titre chez Canuman éditeur. Titre très pirandellien et fort éloquent. Le théâtre aime se représenter lui-même et le cinéma l'imite parfois.

2 La pièce peut contenir un personnage de comédien. Catherine Treilhou-Balaudé et Marie Miguet l'étudient dans Amy Robsart de Victor Hugo et dans Savannah Bay de Marguerite Duras. Catherine Treilhou-Balaudé montre que le comédien Flibbertigibet est une non-personne, un malfaisant involontaire et que son discours contient une critique de la tragédie et du mélodrame. Marie Miguet prouve que la comédienne Madeleine ne distingue plus tout à fait le théâtre de la réalité et que la fin de la pièce est sans doute imaginaire.

3 Les auteurs dramatiques peuvent aussi, d'une manière ou d'une autre, se référer, dans leurs pièces, à d'autres pièces. Le théâtre se prend lui-même comme objet et se suffit à lui-même. Danièle Gasiglia-Laster rappelle que Jacques Prévert introduit dans trois de ses pièces des représentations fictives de pièces bourgeoises pour s'en moquer. Guy Teissier et Robert Jouanny étudient la manière dont différents auteurs canadiens et Henri Bauchau réécrivent et "surthéâtralisent " diverses pièces classiques comme ๔dipe et Dont Juan. Bernard Baritaud rappelle le rôle que joue La Double Inconstance dans La Répétition d'Anouilh et rapproche Anouilh de Salacrou. Daniel Sangsue signale que Stendhal a été tenté lui aussi par le théâtre dans le théâtre.

4 La comédie est parfois une manière d'être du personnage. Chez Sartre, étudié par Margareta Gyurcsik, le personnage, notamment dans Le Diable et le bon dieu, se joue la comédie pour prouver sa liberté. La comédie est aussi, comme le démontre Jean-Marc 
Defays, inséparable du monologue comique de Desproges, Bedos et Devos; ils la pratiquent sous diverses formes depuis l'autoreprésentation jusqu'à l'autodérision.

Certains personnages jouent aussi des comédies non écrites dans la pièce. Ainsi dans Les nègres de Jean Genêt dont Pierre Brunei démonte le mécanisme, les nègres-nègres sont des comédiens devant les nègres-blancs qui les regardent et qui sont eux-mêmes masqués. Le même comportement se retrouve de temps en temps chez Ionesco. Livius Ciocarlie rappelle que le vieux, dans Les Chaises, croit s'adresser à un public alors qu'il se trouve devant des chaises vides. Lucette Desvignes analyse, dans Les Acteurs de bonne foi de Marivaux, la manière dont la comédie fictive se mue en une comédie réelle; certains personnages comme Madame Argante jouent un rôle comique sans s'en douter.

Laurence Brogniez, Scarlette Winter, Arnaud Laster, Frank Wilhelm se posent des questions analogues à propos de films de Philippe Garrel, Robbe-Grillet, Prévert et Cayatte, François Leterrier, François Truffaut. Jeanne Bem relie plus particulièrement le théâtre et le cinéma dans son étude sur Éden-cinéma de Marguerite Duras, pièce de théâtre où l'Éden-cinéma est un espace imaginaire.

7 Le lecteur trouvera là matière à d'amples méditations et ce livre, malgré quelques imperfections de style, le guidera agréablement dans un labyrinthe d'illusions et de miroirs.

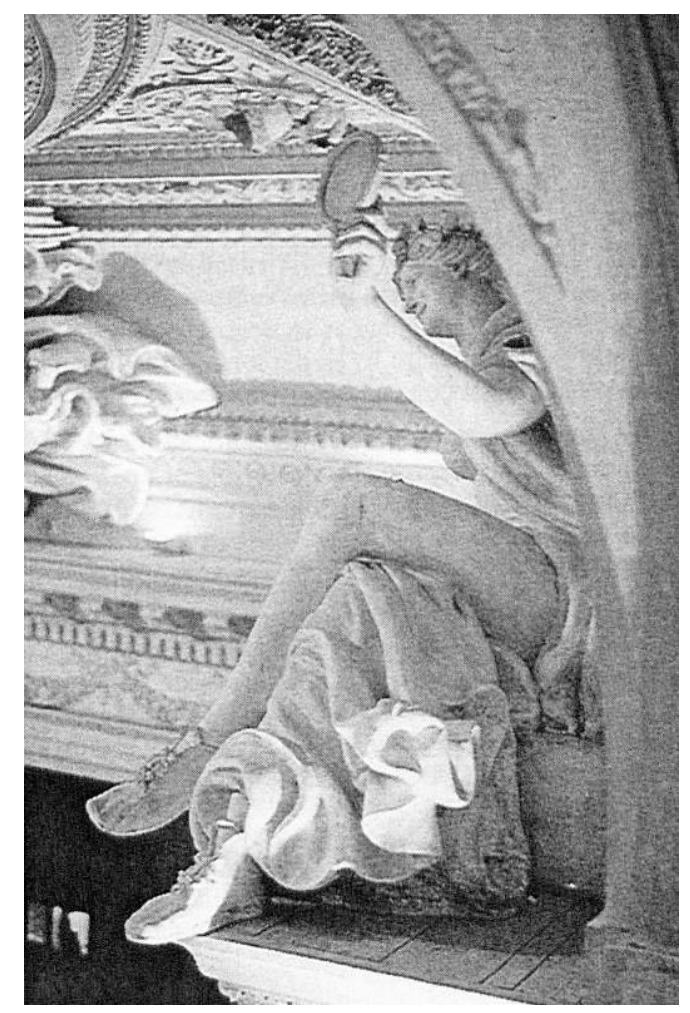

Photo Pierre Clapot 


\section{AUTEURS}

\section{PHILIPPE BARON}

Université de Franche-Comté 